\title{
Basal cell carcinoma - molecular biology and potential new therapies
}

\author{
Maria Kasper, ${ }^{1}$ Viljar Jaks, ${ }^{1,2}$ Daniel Hohl, ${ }^{3}$ and Rune Toftgård'
}

${ }^{1}$ Karolinska Institutet, Center for Biosciences and Department of Biosciences and Nutrition, Novum, Huddinge, Sweden. ${ }^{2}$ Institute of Molecular and Cell Biology, University of Tartu, Tartu, Estonia. 3University Hospital of Lausanne (CHUV), Department of Dermatology, Lausanne, Switzerland.

\begin{abstract}
Basal cell carcinoma (BCC) of the skin, the most common malignancy in individuals of mixed European descent, is increasing in incidence due to an aging population and sun exposure habits. The realization that aberrant activation of Hedgehog signaling is a pathognomonic feature of BCC development has opened the way for exciting progress toward understanding BCC biology and translation of this knowledge to the clinic. Genetic mouse models closely mimicking human BCCs have provided answers about the tumor cell of origin, and inhibition of Hedgehog signaling is emerging as a potentially useful targeted therapy for patients with advanced or multiple BCCs that have hitherto lacked effective treatment.
\end{abstract}

\section{Introduction}

Description of basal cell carcinoma. In 1827 Arthur Jacob termed the skin tumor that we now call basal cell carcinoma (BCC) "Ulcus rodens" (1). In 1900, Krompecher described BCC as a malignant, locally invasive, and destructive cancer and named it "Carcinoma epitheliale adenoides"; he then went on to pioneer the classification of skin tumors using histogenetic principles, three years later coining the term "Basalzellenkrebs" $(2,3)$, a term indicating that the tumor originated in the basal layer of the epidermis or hair follicle (HF). In contrast, in 1910, Mallory used the term "hair matrix tumor" to specify the follicular origin of BCC (4), illustrating the long-standing controversy and uncertainty about the cellular origin of BCC. The locally aggressive, but overall rather benign, course of the disease, with metastasis being largely absent, was similarly noted early on and spurred the debate as to whether BCC could be considered a truly malignant cancer or a "semi-malignant" tumor. The WHO classification has retained the name "BCC" since 1974 (5). BCC is the most common human cancer and accounts for about two-thirds of all skin cancers in patients of mixed European descent. In the US this corresponds to approximately one million cases per year $(6,7)$.

Clinical appearance of human BCC and related tumors. The incidence of BCC is strongly associated with exposure to UV radiation; tumors develop primarily on the sun-exposed skin of elderly individuals with fair skin phototypes, are rarely found on palmoplantar surfaces or in children, and never appear on the mucosa. Additional established risk factors include ionizing radiation (IR), arsenic, and immune suppression (8, 9). Clinically, BCCs appear as pearly and telangiectatic papules or nodules with or without ulceration, or as indurated, erythematous, or ulcerated patches with a discrete papular border, and may be pigmented.

Morphologically, BCC encompasses a group of epithelial intradermal tumors characterized by a primary cellular component that resembles the undifferentiated basal cells of the epidermis and its appendages. These basaloid cells are often arranged in palisades at the tumor periphery, are separated from the surrounding stroma by optically empty spaces, and form nodules, bands, or strings,

Authorship note: Maria Kasper and Viljar Jaks contributed equally to this work. Conflict of interest: The authors have declared that no conflict of interest exists. Citation for this article: J Clin Invest. 2012;122(2):455-463. doi:10.1172/JCI58779. with some continuity with the overlying epithelium in most cases. Visible desmosomal intercellular structures are absent, and the tumor cells have little cytoplasm and show chromatin-rich nuclei with frequent mitoses when compared with normal skin; however, they are often apoptotic, consistent with slow tumor growth (10).

BCCs display different morphological growth patterns: superficial, nodular, micronodular, infiltrating, sclerosing, and fibroepithelial (Figure 1). Nodular BCCs in particular may resemble adnexal tumors or, in some regions, squamous cell carcinoma, as these BCCs demonstrate a variety of types of differentiation including basosquamous or metatypical, cystic, adenoid, pigmented, and infundibulocystic differentiation.

The diversity in the phenotypic appearance of BCCs indicates that the cell of origin may be a stem or progenitor cell. Moreover, these observations raise the question as to whether BCC is a monoclonal tumor or whether it is the result of field cancerization. Studies investigating clonal patterns of X chromosome inactivation suggest that the majority of BCCs do represent monoclonal tumors and that anatomically distinct BCCs may sometimes share the same cellular origin $(11,12)$.

Genetics of BCC development. Major advances in our understanding of the molecular changes leading to BCC formation have come from studies of patients with a hereditary predisposition to BCC development. As early as 1894, Jarisch and White described patients with features typical of the autosomally inherited syndrome $(13,14)$ now known as basal cell nevus syndrome (BCNS, also known as Gorlin syndrome), which was later described in detail by Robert Gorlin and others $(15,16)$. The birth incidence of BCNS in the United Kingdom is 1 in 19,000 (17); BCNS patients typically develop numerous BCCs starting at a young age and are prone to developing other tumors including medulloblastomas. Soon after the cloning of the Hedgehog $(\mathrm{Hh})$ receptor Patched 1 (PTCH1) as the BCNS disease gene $(18,19)$, it became clear that a majority, if not all, of sporadic BCCs show abnormal activation of the Hh pathway $(9,20)$, ascribing constitutive activation of the $\mathrm{Hh}$ signaling pathway (Figure 2 and reviewed in ref. 21) as a prerequisite for the development of a BCC.

Other genetic syndromes such as Bazex-Dupré-Christol syndrome (22), Rombo syndrome (23), cartilage-hair hypoplasia (CHH) (24), and xeroderma pigmentosum (XP) (25) are associated with a high risk for BCC (reviewed in ref. 26), illustrating the 


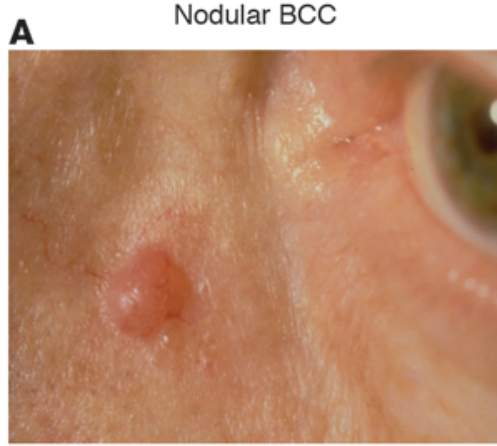

B

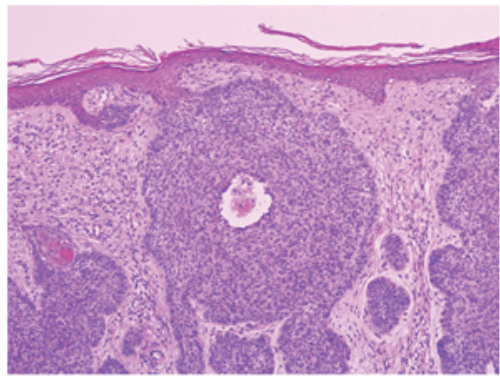

C

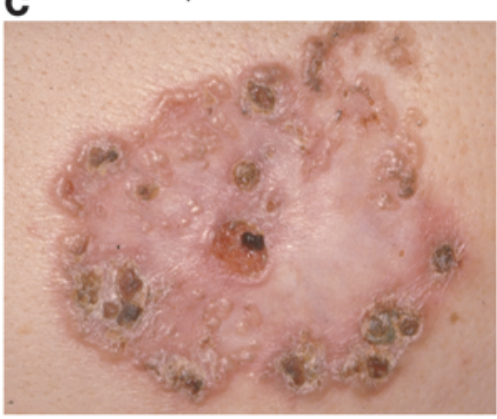

D

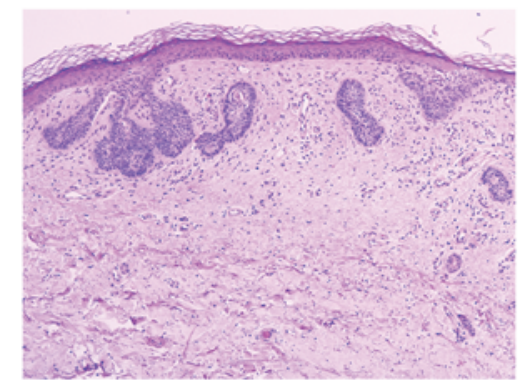

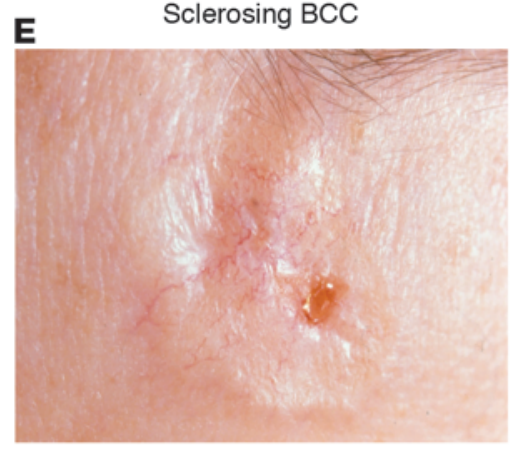

$\mathbf{F}$

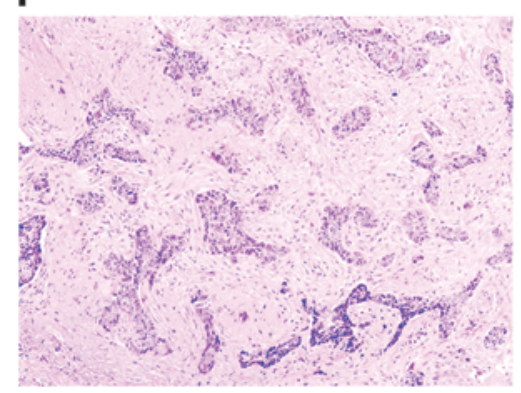

Figure 1

Major subtypes of human BCC. (A-E) Macroscopic (A, C, and E) and microscopic (B, D, and F) appearance of nodular (A and B), superficial (C and $\mathbf{D})$, and sclerosing ( $\mathbf{E}$ and $\mathbf{F})$ human BCCs. Original magnification, $\times 100(\mathbf{B}, \mathbf{D}$, and $\mathbf{F})$.

involvement of additional genetic factors and pathways such as DNA repair $(\mathrm{XP})$ and telomere maintenance $(\mathrm{CHH})$.

Crosstalk between $\mathrm{H} h$ and other molecular signaling pathways in BCC. The Wnt pathway has a well-established role in normal HF development and cycling, and both human and mouse BCCs have increased levels of $\beta$-catenin, a critical mediator of Wnt signaling $(27,28)$. In accordance with these observations, overexpression of the potent Wnt antagonist, Dkk1, in mouse epidermis resulted in the inhibition of benign Hh-driven hamartomas, showing that active Wnt signaling is required for their growth (29).

In line with its importance in epidermal development, the EGFR/ MEK/ERK pathway has been shown to modulate GLI-dependent transcription in human keratinocytes (30) and to synergistically induce oncogenic transformation of human keratinocytes (31). Additionally, the tumor suppressor p53 may influence BCC development. The complete loss of $p 53$ was shown to result in upregulated expression of the Hh pathway mediator smoothened (Smo) in the interfollicular epidermis (IFE) in mice, thereby making these keratinocytes receptive to BCC induction (32).

Finally, the correct cellular context is important for the persistent growth of BCCs, and epithelial-stromal interactions play a role in creating a favorable microenvironment. Stromal cells, isolated from human BCCs, express high levels of gremlin 1, which antagonizes the pro-differentiation factors BMP2 and BMP4, synthesized in the BCC tumor cells, thereby sustaining tumor growth (33).

\section{Modeling the disease}

Genetic mouse models represent a major advance in cancer research as they provide the possibility of studying tumors in the context of the entire organism. The study of BCC tumorigenesis in mice has been hindered by the inexplicable failure of mutagenic chemicals and UV or IR to induce BCCs (34). However, genetically engineered mouse models for $\mathrm{BCC}$ provide the option to investigate the molecular mechanisms of BCC formation and progression and the identification of the cells of origin. Due to the obligate dependency of BCCs on activated Hh signaling, all current BCC mouse models target different components of the Hh signal transduction pathway, and these are summarized in Tables 1 and 2 . In this context it is important to note that tumors developing in the mouse may not always fully mimic human BCCs but represent various stages in a spectrum of benign to malignant Hh pathwayinduced BCC-like tumors, likely reflecting a similar variation in humans, where benign hamartomas and BCCs appear to be driven by different levels of Hh pathway activation (35-38).

Cell of origin and morphological diversity of BCC. Stem and progenitor cells are thought to be the most probable sources of tumor initiation due to their longevity and ability to self-renew $(39,40)$. In the skin, several populations of cells with stem cell (SC) properties have been discovered; however, defined SC markers are, as yet, limited to the HF (Figure 3; reviewed in refs. 41, 42). A collection of recent publications describes the use of mouse genetics to identify BCC cells of origin using Cre-mediated cell-specific targeting, either by lineage tracing, which involves the genetic labeling of cells, or by the activation of oncogenic Hh signaling in distinct skin cell populations (Figure 3). The identification of tumor cells of origin and, equally importantly, cells that cannot initiate tumorigenesis, will make it possible to pinpoint molecular mechanisms that either predispose or protect a cell from oncogenic transformation.

In the first publication to address the cellular origin of BCC, Youssef et al. used mice conditionally expressing SmoM2 (43), a constitutively active variant of Smo (44). When SmoM2 expression was activated in different cell compartments in the epidermis, 
A

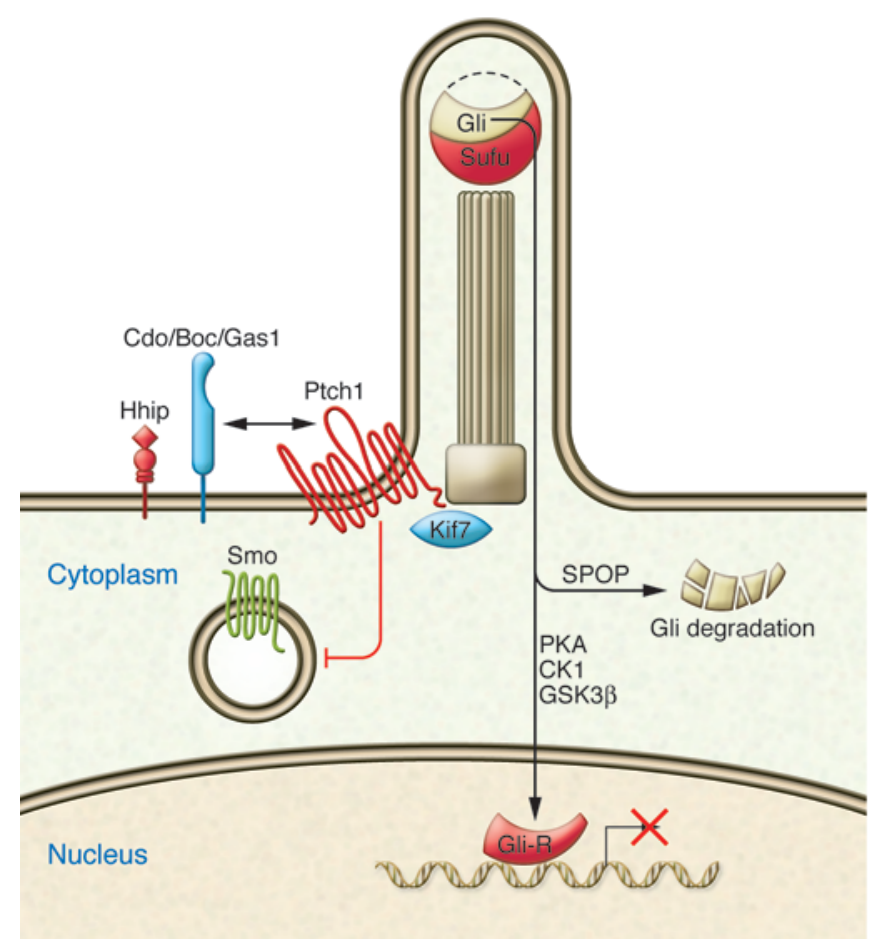

B

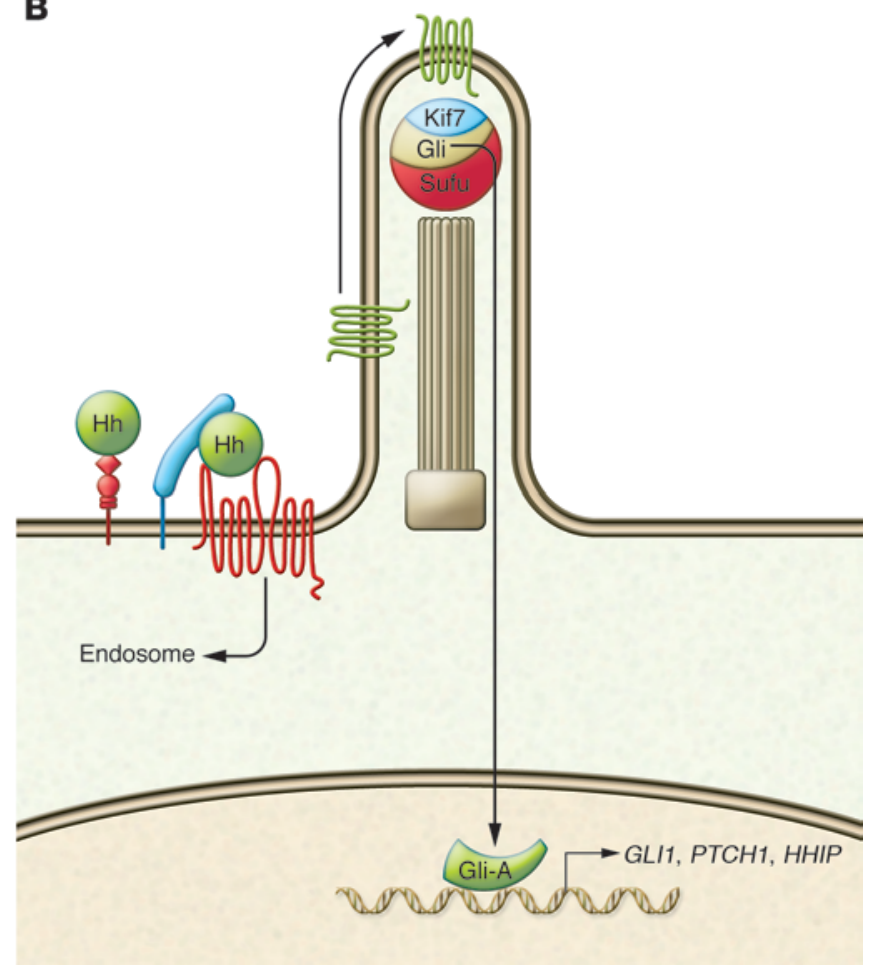

Figure 2

The Hh signaling pathway - a simplified model. (A) In its "off" state, Ptch1 represses Smo activity. Gli2 and Gli3, effectors of the Hh pathway, are phosphorylated by a kinase cascade, which includes PKA, CK1, and GSK3 $\beta$, and are directed to the proteasomal degradation pathway via the SPOP complex. A fraction of the Gli2/3 protein is processed into a repressor form, Gli-R, which inhibits Hh target gene transcription. (B) Hh ligand binding to Ptch1 abrogates its inhibitory effect on Smo, allowing Smo to translocate into the primary cilium and induce accumulation of the Gli-Sufu complex at the tip of the primary cilium. Activation of the Hh pathway results in accumulation of Gli-A and initiation of the transcription of Hh target genes such as PTCH1, GLI1, and HHIP.

including HF SCs (Table 2), only cells originating in the IFE and the upper infundibulum produced full-blown BCCs. Importantly, the IFE-derived tumors also exhibited an HF-like protein expression pattern, demonstrating that the biochemical and morphological characterization of tumor cells may be misleading when used to identify the cellular origin of cancers $(29,43)$.

These same mouse models (employing conditional expression of SmoM2 in K14- or K15-positive cells; Table 2) were used to study the effect of wound healing on BCC development (45). It was previously reported that active wound repair recruits HF cells for re-epithelialization (46-48). In K15-SmoM2 skin, which targets SmoM2 expression mostly to the HFs, the HFs exhibited only occasional basaloid lesions in the bulge and the hair germ (HG) $(43,49)$. Intriguingly, during wound healing, the HF SmoM2-expressing cells are mobilized to the IFE, where they drive BCC formation and form tumors (45). Why does SmoM2 induce tumors in the IFE upon wounding but not in the intact bulge or HG? One possible explanation is that the bulge microenvironment suppresses SmoM2-mediated oncogenesis, as Gli1 and Gli2 mRNAs, which encode Hh pathway effector proteins downstream of Smo, are upregulated in IFE-associated tumors but not in HFs (45).

Our group has also addressed the question of the BCC cell of origin and the effect of wounding on tumor growth (ref. 50 and Table 2). Overexpression of human GLI1 under the control of the $\mathrm{K} 5$ promoter resulted in $\mathrm{BCC}$ formation, preferentially in the IFE, but also in the HF. Lineage-tracing of $\mathrm{Lgr}^{+} \mathrm{SCs}$, which give rise to the bulge and HG, showed that in this BCC model, HF- and IFEassociated lesions had distinct cells of origin, as no $\mathrm{Lgr} 5^{+}$-traced lesions were found in the IFE. However, Lgr5-labeled HF cells were able to give rise to BCCs in the IFE upon wounding, in line with the study by Wong et al. (45). In the Lgr5Cre-Ptch $1^{f l / f l}$ mouse model, Ptch1 deletion in Lgr5-expressing HF SCs resulted in the formation of locally restricted basaloid proliferations in the lower part of the HF. In wounded skin, Ptch1-deficient $\mathrm{Lgr} 5^{+}$cells were again recruited to the wound sites in the IFE, where they induced de novo basaloid lesions (50). Thus, the concept that wounding is an important factor in tumor development, postulated 150 years ago (52), also appears applicable to BCC development.

Despite similar molecular pathogenesis, a considerable morphological heterogeneity exists among BCCs (53). How do these morphological differences occur? By comparing two different BCC models, Grachtchouk et al. found that BK5-GLI2 mice (54) with strong Hh signaling developed full-featured BCCs, while the weaker Hh signal in $\triangle K 5$-SMO-M2 mice resulted in follicular hamartomas (35). Furthermore, a recent, more detailed study from the same group revealed that activated SmoA1 expression in the HF does not give rise to BCC-like lesions in the HF and that low levels of GLI $2 \Delta \mathrm{N}$ expression throughout the basal compartment do not lead to nodular BCCs in the HF (in contrast to the model with high GLI2 $\triangle \mathrm{N}$ expression), but to slow-growing basaloid follicular ham- 
Table 1

General mouse models used to study BCC formation

\begin{tabular}{|c|c|c|c|c|c|}
\hline $\begin{array}{l}\text { Cell targeting } \\
\text { alleles }\end{array}$ & $\begin{array}{l}\text { Effector } \\
\text { alleles }\end{array}$ & $\begin{array}{c}\text { Start of } \mathrm{Hh} \\
\text { pathway modulation }\end{array}$ & $\begin{array}{l}\text { Additional } \\
\text { treatment }\end{array}$ & Pathology & Reference \\
\hline K14 & Shh Tg & $\mathrm{E} 0^{\mathrm{A}}$ & No & BCC-like lesions & 89 \\
\hline hK5 & hSM0-M2 Tg & $\mathrm{EO} 0^{\mathrm{A}}$ & No & BCC-like lesions & 90 \\
\hline All & Ptch1+- & E0 & No & Trichoblastomas & 91 \\
\hline All & Ptch1+- & E0 & UV, $\gamma$-IR, X-ray & BCC, trichoblastomas & 91 \\
\hline BK5 & hGLI1 Tg & $\mathrm{EOA}$ & No & $\begin{array}{l}\text { BCC, trichoepitheliomas, } \\
\text { cylindromas, trichoblastomas }\end{array}$ & 36 \\
\hline BK5 & mGli2 Tg & $\mathrm{E} 0^{\mathrm{A}}$ & No & BCC & 54 \\
\hline BK5 & mGli2 $\Delta \mathrm{N} 2 \mathrm{Tg}$ & $\mathrm{E} 0^{\mathrm{A}}$ & No & $\begin{array}{l}\text { BCC, trichoblastomas, cylindromas, } \\
\text { basaloid follicular hamartomas }\end{array}$ & 92 \\
\hline$\triangle \mathrm{BK} 5$ & hSM0-M2 Tg & $\mathrm{E} 0^{\mathrm{A}}$ & No & Basaloid follicular hamartomas & 35 \\
\hline All & $\mathrm{Ptch}^{+-}$ & E0 & No & Basaloid hyperproliferations & 93 \\
\hline All & $\mathrm{Ptch}^{+/-}$ & E0 & X-ray & BCC (nodular and infiltrative) & 93 \\
\hline K5tTA (bovine) & TREmGli2 Tg & $\mathrm{EOA}$ & DOX off & BCC & 75 \\
\hline All & Sufu+/- & E0 & No & BCC, basaloid follicular hamartomas & 94 \\
\hline K6a-Cre & Ptch $1^{f \mid / f l}$ & $\mathrm{EOA}$ & No & ORS hyperplasia & 27 \\
\hline K6a-Cre & Ptch1fl/fl & E0 & Retinoic acidB & BCC-like lesions & 27 \\
\hline K14-Cre & Ptch $1^{f \mid / f l}$ & EOA & & BCC-like lesions & 95 \\
\hline Mx1-Cre & $\operatorname{Ptch} 1^{f \mid / f l}$ & Various & $\operatorname{poly}(\mathrm{I}: \mathrm{C})^{\mathrm{C}}$ & BCC-like lesions & 95 \\
\hline CAGGS-CreER & fl-STOP-fl-SmoM2-YFPD & P10 & No & BCC-like lesions & 96 \\
\hline K14-CreERT & fl-STOP-fl-SmoM2-YFPD & P30-P35 & No & BCC-like tumors & 97 \\
\hline K14-CreERT & fl-STOP-fl-SmoM2-YFPD,E & P30-P35 & No & Inhibition of BCC-like tumors & 97 \\
\hline K14-CreERT & CLEG2-condF & P30-P35 & No & BCC-like tumors & 97 \\
\hline K14-CreERT & CLEG2-condE,F & P30-P35 & No & Enhanced BCC-like tumors & 97 \\
\hline
\end{tabular}

AEffective promoter activation is dependent on temporal regulation during embryogenesis (e.g., K14 starts at E9.5). ${ }^{\mathrm{B} T o}$ activate K6 expression in the IFE and ORS at P32. CTo activate Mx1 promoter via interferon response. DFusion protein of mSmoM2 with YFP inserted into the Rosa26 locus. EAdditional allele is Kif3a ${ }^{\text {fl/- }}$. FCLEG2 denotes Myc-tagged, constitutively active human GLI2.

artomas resembling the tumors found in $\triangle K 5$-SMO-M2 mice (ref. 37 and Table 2). These observations support the suggestion that, downstream of Ptch1, the level of Hh pathway activation, rather than the exact molecular target, is crucial in determining the BCC subtype. It is worth noting that high levels of GLI2 $\Delta \mathrm{N}$ expression in the bulge and HG rapidly lead to nodular tumors, most likely initiated in the lower bulge and the HG (37), and the HG may also be the source for tumor-initiating cells in $\operatorname{Lgr} 5 \mathrm{Cre}$-Ptch $1^{f l / f l}$ mice (50). The lower bulge and HG harbor cells with active Hh signaling in telogen $(55,56)$, which may represent a cell population that is preferentially susceptible to Hh pathway-driven tumorigenesis.

The influence of the hair cycle phase on BCC growth is also important, and the authors of three studies have presented direct evidence that BCC development occurs preferentially, but not exclusively, during anagen phase $(37,57,58)$. One reason may be that cells located in the outer root sheath (ORS) of anagen HFs can give rise directly to nodular BCCs, supporting the idea that this compartment contains cells capable of transformation by oncogenic Hh signaling and, therefore, provides an expanded pool of potential tumor progenitors.

Together, the results obtained using mouse models to study BCC development have so far revealed that oncogenic Hh signaling can drive BCC-like tumor formation in several different epithelial progenitor populations in skin, although the morphology and the final outcome of BCC development are influenced by the cell of origin, the mutated Hh pathway member, and the strength of oncogenic Hh signaling.

\section{New therapies}

Highly efficient treatment modalities such as surgery that aims at complete extirpation, radiotherapy, curettage, cryotherapy, photodynamic therapy, and topical applications of imiquimod or 5-fluorouracil are available and effective for the great majority of BCC patients $(9,59)$. However, the occurrence of locally aggressive and invasive tumors, a bleak prognosis upon metastatic spread, a significant rate of recurrence often associated with increased aggressiveness, as well as the multitude of tumors appearing in high-risk populations such as BCNS patients, provide compelling reasons to search for new preventive and therapeutic avenues (60).

$H$ Hignaling as a target for new BCC therapies. The first evidence that the Hh signaling pathway is sensitive to inhibition by small molecules stemmed from the observation of cyclopia in lambs, induced by the maternal ingestion of corn lilies (Veratrum californicum) (61), followed by the demonstration that the active compound, cyclopamine, inhibits Hh signaling (62) and binds to SMO (63). Initial studies showed that, in addition to $\mathrm{Hh}$ inhibition in various in vitro systems, the oral administration of cyclopamine reduced the growth and development of BCCs in $P t c h 1^{+/-}$mice exposed to UV irradiation (64), and its topical application to human BCCs can induce regression (65).

New derivatives of cyclopamine with improved pharmaceutical properties are now in clinical trials (Table 3 and ref. 66). Excellent results were obtained with the orally administered SMO inhibitor GDC-0449 (vismodegib; Table 3) in a phase I trial of patients with locally advanced or metastatic BCC $(67,68)$. Phase II results 


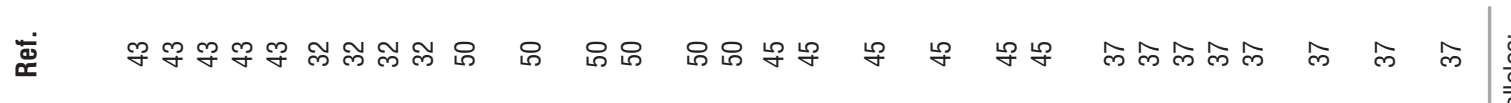

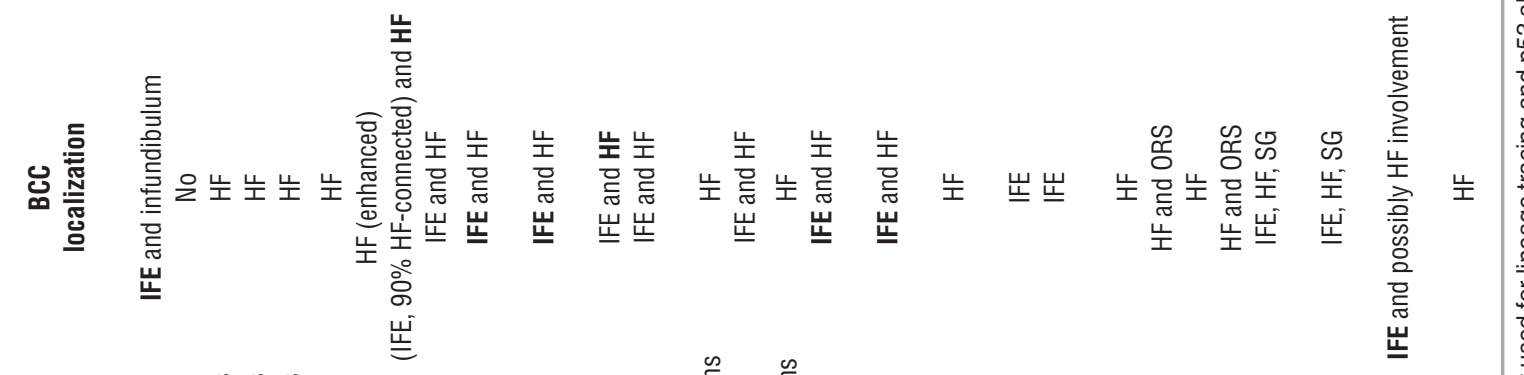

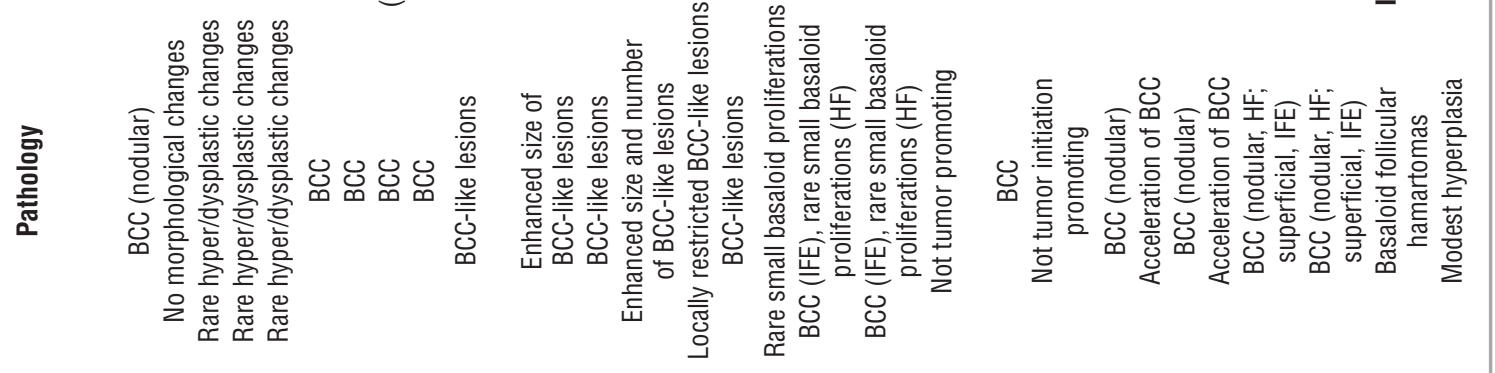

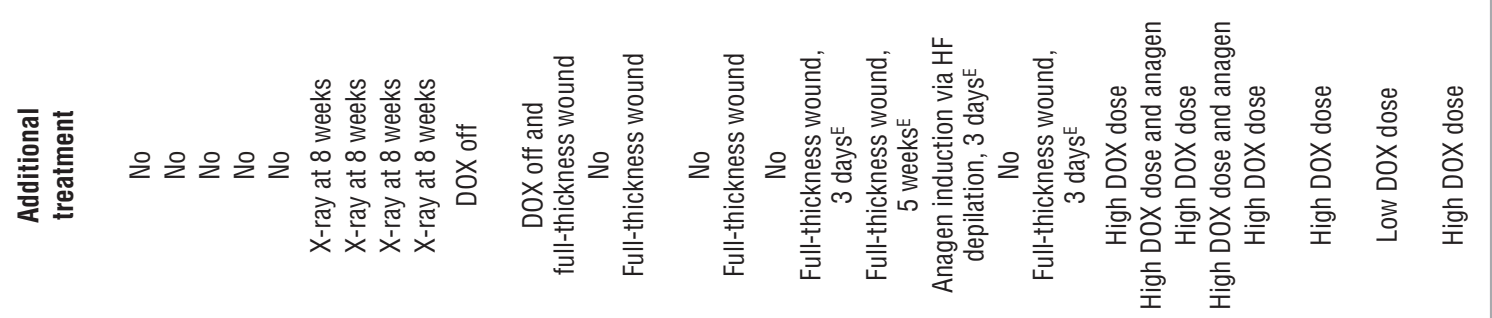

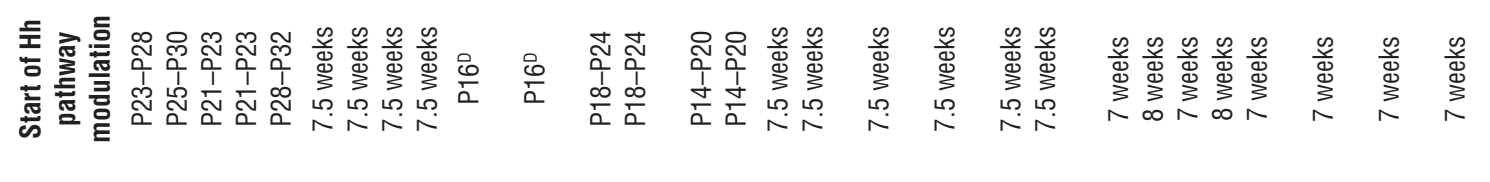

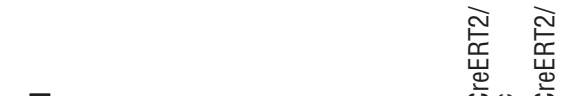

高

ปัँ 产 㟋

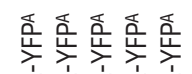

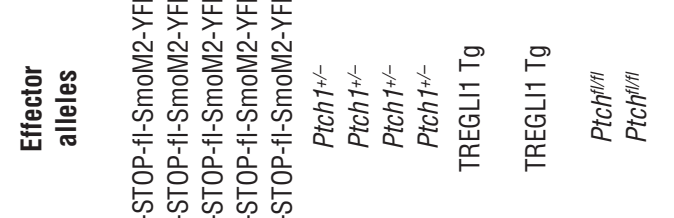

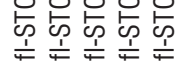

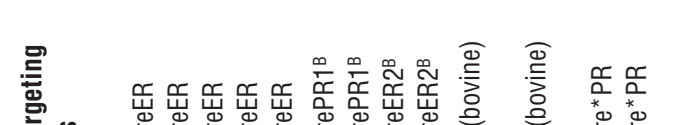

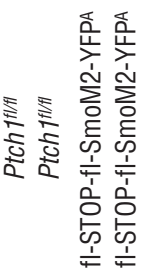

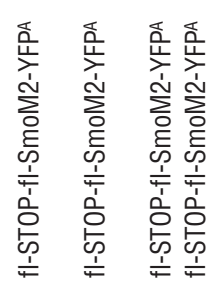

돈

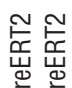

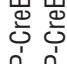

峁 这

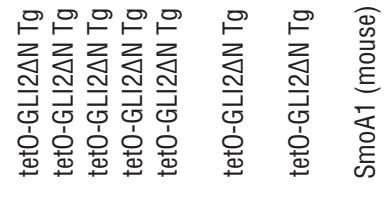

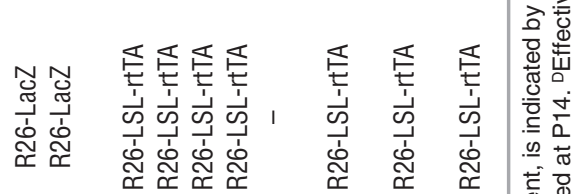

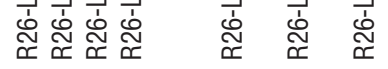




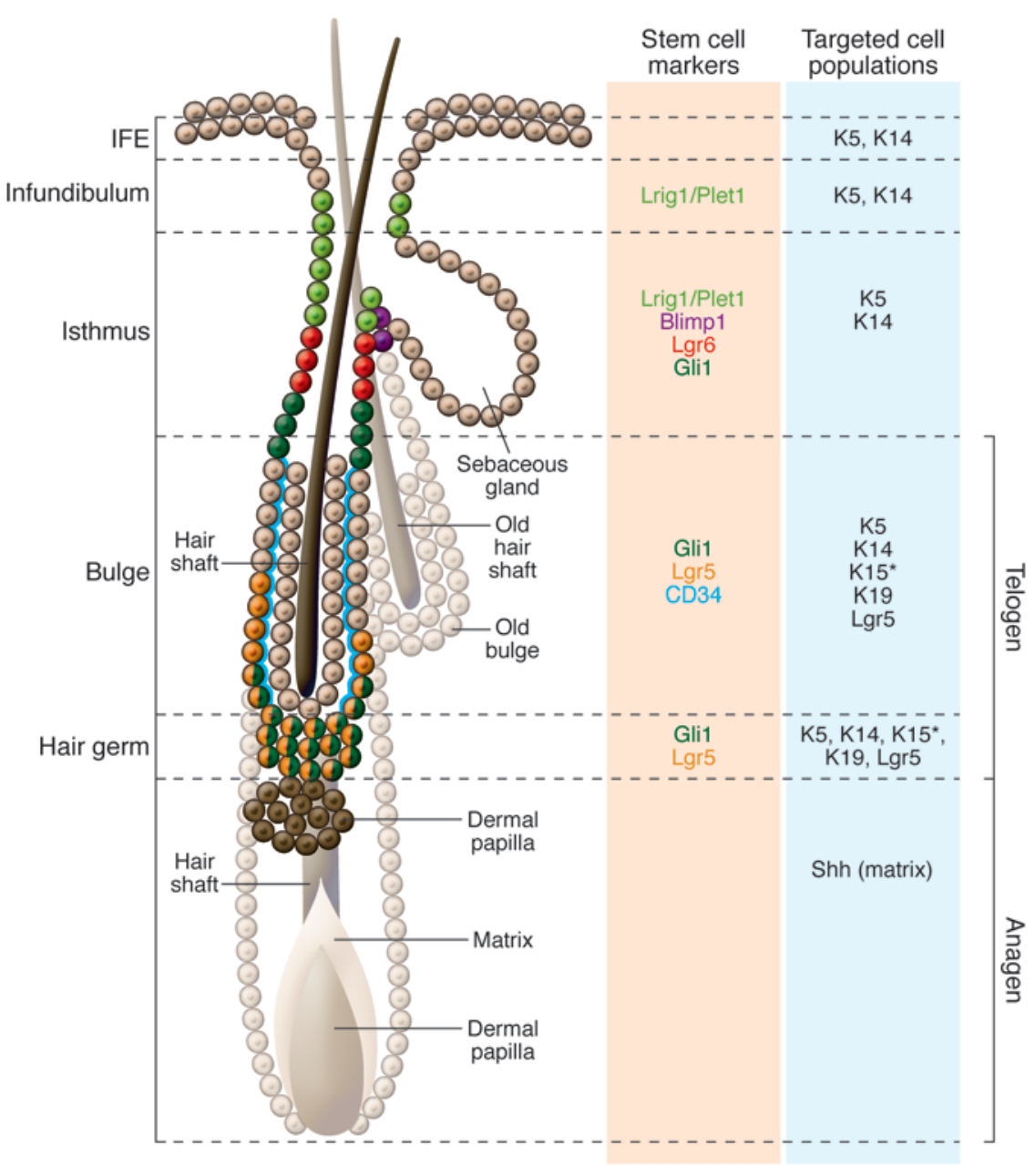

\section{Figure 3}

The HF and its morphological units, stem cell compartments, and targeted cell populations. The targeted cell populations are defined by endogenous or transgene promoter activities. K15* denotes a truncated version of the K15 promoter, restricted in its activity to the bulge area. using GDC-0449 in patients with locally advanced or metastatic BCC (69) and in BCNS patients with multiple BCCs (70) were so promising that the Data Safety Monitoring Board recommended ending the placebo arm of the BCNS study in light of the differences between the study arms. Importantly, no resistance has so far been reported. In addition, a phase I study of IPI-926 (Table 3) given orally to patients with advanced types of BCC also resulted in a positive response rate (71).

In the studies investigating systemic treatment with SMO inhibitors, a common set of adverse effects has been observed, including muscle spasms, loss of taste (dysgeusia), hair loss, fatigue, nausea, and hyponatremia. It is likely that hair loss and altered taste, at least, are related directly to SMO inhibition, since Hh signaling is known to be active in HFs and taste buds $(72,73)$. One way to avoid or reduce such effects might be to use these inhibitors topically, thus limiting systemic exposure. A small, short-term study in BCNS patients with nodular and superficial BCC, employing twice-daily topical treatments of the SMO inhibitor LDE225 for four weeks, resulted in a positive response, and BCC regression correlated with a decrease in Hh target gene expression in most treated tumors (74). No treatment-related side effects were noted, consistent with low levels of systemic exposure to the inhibitor.

A potential caveat associated with the use of Hh pathway antagonists for the treatment of BCC is the possibility that, while treatment may result in a dramatic reduction in tumor mass, a small number of residual cells that are relatively insensitive to Hh signal inhibition may persist so that treatment may not be curative. The existence of such a cell population has been shown both in a mouse BCC model (75) and in a clinical trial of the SMO inhibitor LDE225 (ref. 74 and Table 3).

Another concern is the development over time of resistance to SMO inhibitors used in treatment, which may or may not involve mechanisms similar to those that render certain BCCs refractory to treatment from the start. Medulloblastoma is another tumor type in which Hh signaling is frequently activated by mutations in PTCH1 or SMO, and the treatment of one patient with a medulloblastoma carrying PTCH1 mutations with GDC-0449 led to rapid but transient tumor regression (76). Subsequently, it was found that an amino acid substitution in SMO that had no effect on $\mathrm{Hh}$ signaling but disrupted the ability of GDC-0449 to bind SMO and suppress this pathway was the underlying cause of the relapse (77). Studies in animal models confirmed that the development of resistance can be caused by mutations in Smo as well as by the amplification of downstream genes such as Gli2 and cyclin D1 $(78,79)$. Potential methods of overcoming such resistance involve the use of alternative SMO inhibitors (79) such as the FDA-approved antifungal drug itraconazole, which was recently found to inhibit $\mathrm{Hh}$ signaling by binding to SMO at a site different from cyclopamine and to delay BCC development in $\mathrm{Ptch} 1^{+/-}$mice (80). At present, itraconazole is being evaluated as a possible treatment for BCC 
Table 3

Emerging BCC therapies

\begin{tabular}{|c|c|c|c|c|c|}
\hline Agent/compound & Target & Condition/patient group studied & Study phase & ClinicalTrials.gov ID & Reference \\
\hline \multicolumn{6}{|c|}{ SMO inhibitors in clinical trials } \\
\hline GDC-0449A & SMO & BCNS patients & II & NCT00957229 & 70 \\
\hline GDC-0449 & SMO & Locally advanced or metastatic BCC & II & NCT01367665 & 69 \\
\hline GDC-0449 & SMO & Operable BCC & II & NCT01201915 & - \\
\hline GDC-0449 & SMO & BCC & II & NCT00959647 & - \\
\hline GDC-0449 & SMO & Advanced BCC & II & NCT00833417 & - \\
\hline GDC-0449 & SMO & Locally advanced or metastatic BCC & II & NCT01160250 & - \\
\hline LDE-225 & SMO & BCNS patients & II & NCT00961896 & - \\
\hline LDE-225 & SMO & Advanced solid tumors (BCC, medulloblastoma) & I & NCT01208831 & - \\
\hline LDE-225 & SMO & Advanced solid tumors (BCC, medulloblastoma) & I & NCT00880308 & - \\
\hline LDE-225 & SMO & Sporadic superficial and nodular BCC & II & NCT01033019 & - \\
\hline LDE-225 & SMO & Locally advanced or metastatic BCC & ॥ & NCT01327053 & - \\
\hline LDE-225 & SMO & BCNS patients & II & NCT01350115 & - \\
\hline LDE-225 & SMO & BCNS patients & Preclinical & - & 74 \\
\hline Cur61414 & SMO & $\begin{array}{c}\text { UV-treated Ptch1+/- mice; } \\
\text { Ptch1+-/K14-CreERT2-p53 } 3^{1 / f t} \text { mice exposed to IR }\end{array}$ & Preclinical & - & 98,99 \\
\hline Cur61414 & SMO & Superficial and nodular BCC & I & - & 99 \\
\hline IPI-926 & SMO & BCC (including locally advanced or metastatic) & । & NCT00761696 & 71 \\
\hline BMS-833923 & SMO & Advanced or metastatic BCC & I & NCT00670189 & - \\
\hline TAK-441 & SMO & Advanced BCC & 1 & NCT01204073 & - \\
\hline Itraconazole & SMO & BCC & II & NCT01108094 & - \\
\hline \multicolumn{6}{|c|}{ Downstream Hh pathway inhibitors } \\
\hline GANT 58, GANT 61 & $1 \quad$ GLI & NA & Preclinical & - & 81 \\
\hline Arsenic trioxide & GLI & NA & Preclinical & - & 83,84 \\
\hline $\mathrm{HPI} 1 / 2 / 3$ & GLI & NA & Preclinical & - & 82 \\
\hline $\mathrm{HPI} 4$ & Ciliogenesis & NA & Preclinical & - & 82 \\
\hline \multicolumn{6}{|l|}{ Other agents } \\
\hline Vitamin D3 & SM0/cell proliferation & BCC & III & NCT01358045 & - \\
\hline Tazarotene & RAR- $\beta /$ RAR- $\gamma$ & BCC on chest and back of BCNS patients & $\|$ & NCT00783965 & - \\
\hline Tazarotene & RAR- $\beta /$ RAR- $\gamma$ & BCC on face of BCNS patients & II & NCT00489086 & - \\
\hline
\end{tabular}

ADrug name vismodegib. BBCCs failed to show signs of clinical response or significant GLI1 target gene inhibition, likely due to inadequate drug absorption.

in a phase II trial (Table 3). Alternatively, blocking other signaling pathways in resistant tumors may be effective, and in preclinical studies of medulloblastomas, PI3K inhibition has emerged as a promising possibility $(78,79)$.

In situations in which Hh pathway activation occurs downstream of SMO, targeting the final effectors in the pathway, such as the GLI transcription factors, would be preferable. The potential viability of this strategy has been demonstrated by the identification of small molecule inhibitors acting at the level of GLI, or at alternative steps downstream, and independent of SMO (refs. 81,82 , and Table 3 ). Interestingly, in two studies it has been found that arsenic trioxide, in clinical use for the treatment of acute promyelocytic leukemia, can inhibit Hh signaling at the GLI protein level, although the exact mechanism remains controversial (83, 84). However, given the diverse set of targets for arsenic trioxide, it will be challenging to delineate critical targets in an in vivo setting, and existing side effects may limit its attractiveness as a treatment for BCC; curiously, arsenic exposure is also a known risk factor in BCC development (85).

Given the key role of primary cilia in the transduction of the Hh signal (Figure 2), inhibitors of ciliogenesis or ciliary function represent a further means of intervention in BCC tumorigenesis, and a small molecule blocking ciliogenesis has been identified as an Hh inhibitor (ref. 82 and Table 3). Again, the multiple cellular effects expected as a result of cilia disruption will place obstacles in the way of obtaining specificity.

Other potential new BCC therapies. Vitamin D3 has been shown to block Hh signaling in vitro and in murine BCCs in vivo, presumably at the level of SMO, in a manner independent of vitamin $\mathrm{D}$ receptor (VDR) activation $(86,87)$. The enhanced differentiation of keratinocytes induced via VDR activation is an additional and well-established effect of vitamin D3. A phase III trial combining topical vitamin D3 therapy and treatment with an anti-inflammatory agent in patients with nodular BCC has been initiated (Table 3).

Finally, topical treatment with the RARB/RARG-selective retinoid tazarotene has been shown to reduce the number and size of early BCC lesions in irradiated $P t c h 1^{+/-}$mice $(87,88)$, and its efficacy in the control of BCC development in BCNS patients is under study in two phase II clinical trials (Table 3).

To summarize, early clinical results targeting the Hh signaling pathway are very promising, especially in regard to BCC treatment and chemoprevention in BCNS patients and for the treatment of locally aggressive or metastatic BCC. However, we still do not have the answer to several important questions: (a) Will treatment truly result in the eradication of BCCs, or will dormant tumor cells remain? (b) What are the major resistance mechanisms in BCCs? (c) Why are a substantial fraction of BCCs refractory to treatment 
from the start? Moreover, the adverse effects that develop with systemic treatment are a significant concern, arguing for the development of local treatment options.

\section{Perspectives}

The great advances in our understanding of BCC biology, derived from deciphering its molecular genetics and from incisive studies using genetic mouse models that closely mimic the human disease, have been translated rapidly into new and promising targeted therapies. At the same time, it is important to realize that we are only just beginning to resolve the long-standing question about the BCC cell of origin. We know from studies in the mouse that SCs and progenitor cells present in the HF can serve as cells of origin, but that additional cells of origin must exist. The marked plasticity of skin epithelial stem cell populations, as revealed upon tissue injury, provides an additional layer of complexity.

Another challenging question begging an answer is the nature of the genetic events that cooperate with an activated Hh signal- ing pathway to determine BCC subtypes, ranging from the benign nodular and superficial forms to aggressive and, in rare cases, metastatic forms. Future studies will certainly provide answers to many of these questions, and it is to be hoped, moreover, that the lessons learned from treating BCC with Hh pathway inhibitors will pave the way for progress in the treatment of other tumors that depend on the presence of active Hh signaling.

\section{Acknowledgments}

We wish to apologize to colleagues whose work was not mentioned or cited in this paper due to space constraints. Support for this work was provided by the Swedish Cancer Society, the Swedish Research Council, and the Swiss National Science Foundation.

Address correspondence to: Rune Toftgård, Karolinska Institutet, Center for Biosciences and Department of Biosciences and Nutrition, Novum, SE-141 83 Huddinge, Sweden. Phone: 46.8.52481053; Fax: 46.8.6081501; E-mail: rune.toftgard@ki.se.
1. Jacob A. Observations respecting an ulcer of peculiar character, which attacks the eyelids and other parts of the face. Dublin Hospital Rep Commun Med Surg. 1827;4:232-239.

2. Krompecher E. Der drüsenartige Oberflachenepithelkrebs. Carcinoma epi- theliale adenoides. Beitr z path Anat u zadg Path. 1900;28:1-41.

3. Krompecher E. Der Basalzellenkrebs. Jena: Gustav Fischer; 1903.

4. Mallory FB. Recent progress in the microscopic anatomy and differentiation of cancer. JAMA. 1910;55(18):1513-1516.

5. Ten Seldam REJ, Helwig EB. Histological Typing of Skin Tumours. Geneva, Switzerland: World Health Organization; 1974.

6. Miller DL, Weinstock MA. Nonmelanoma skin cancer in the United States: incidence. J Am Acad Dermatol. 1994;30(5 pt 1):774-778.

7. Jemal A, Siegel R, eds. Cancer Facts and Figures 2011. Atlanta, Georgia, USA: American Cancer Society, Inc.; 2011.

8. Rubin AI, Chen EH, Ratner D. Basal-cell carcinoma. NEngl J Med. 2005;353(21):2262-2269.

9. Epstein EH. Basal cell carcinomas: attack of the hedgehog. Nat Rev Cancer. 2008;8(10):743-754.

10. Kerr JF, Searle J. A suggested explanation for the paradoxically slow growth rate of basal-cell carcinomas that contain numerous mitotic figures. J Pathol. 1972;107(1):41-44.

11. Shulman O, Laitman Y, Vilan A, Leviav A, Friedman E. Monoclonal origin of anatomically distinct basal cell carcinomas. J Invest Dermatol. 2006; 126(3):676-679.

12. Asplund A, Sivertsson A, Backvall H, Ahmadian A, Lundeberg J, Ponten F. Genetic mosaicism in basal cell carcinoma. Exp Dermatol. 2005;14(8):593-600.

13. Jarisch W. Zur Lehre von den Hautgesschwulsten. Arch Dermatol Syphilol (Berl). 1894;28:162-222.

14. White JC. Multiple benign cystic epitheliomas. J Cutan Genitourin Dis. 1894;12:477-484.

15. Howell JB, Caro MR. The basal-cell nevus: its relationship to multiple cutaneous cancers and associated anomalies of development. AMA Arch Derm. 1959;79(1):67-77.

16. Gorlin RJ, Goltz RW. Multiple nevoid basal-cell epithelioma, jaw cysts and bifid rib. A syndrome. NEngl J Med. 1960;262:908-912.

17. Evans DG, et al. Birth incidence and prevalence of tumor-prone syndromes: estimates from a UK family genetic register service. Am J Med Genet A. 2010;152A(2):327-332.

18. Hahn $\mathrm{H}$, et al. Mutations of the human homolog of Drosophila patched in the nevoid basal cell carcinoma syndrome. Cell. 1996;85(6):841-851.
19. Johnson RL, et al. Human homolog of patched, a candidate gene for the basal cell nevus syndrome. Science. 1996;272(5268):1668-1671.

20. Gailani MR, et al. The role of the human homologue of Drosophila patched in sporadic basal cell carcinomas. Nat Genet. 1996;14(1):78-81.

21. Teglund S, Toftgard R. Hedgehog beyond medulloblastoma and basal cell carcinoma. Biochim Biophys Acta. 2010;1805(2):181-208.

22. Vabres P, de Prost Y. Bazex-Dupre-Christol syndrome: a possible diagnosis for basal cell carcinomas, coarse sparse hair, and milia. Am J Med Genet. 1993;45(6):786

23. Michaelsson G, Olsson E, Westermark P. The Rombo syndrome: a familial disorder with vermiculate atrophoderma, milia, hypotrichosis, trichoepitheliomas, basal cell carcinomas and peripheral vasodilation with cyanosis. Acta Derm Venereol. 1981;61(6):497-503.

24. Makitie O, Pukkala E, Teppo L, Kaitila I. Increased incidence of cancer in patients with cartilage-hair hypoplasia. J Pediatr. 1999;134(3):315-318.

25. Kraemer KH, Patronas NJ, Schiffmann R, Brooks BP, Tamura D, DiGiovanna JJ. Xeroderma pigmentosum, trichothiodystrophy and Cockayne syndrome: a complex genotype-phenotype relationship. Neuroscience. 2007;145(4):1388-1396.

26. Parren LJ, Frank J. Hereditary tumour syndromes featuring basal cell carcinomas. Br J Dermatol. 2011;165(1):30-34.

27. Adolphe C, Hetherington R, Ellis T, Wainwright B. Patched 1 functions as a gatekeeper by promoting cell cycle progression. Cancer Res. 2006;66(4):2081-2088.

28. El-Bahrawy M, El-Masry N, Alison M, Poulsom R, Fallowfield M. Expression of beta-catenin in basal cell carcinoma. BrJ Dermatol. 2003;148(5):964-970.

29. Yang SH, et al. Pathological responses to oncogenic Hedgehog signaling in skin are dependent on canonical Wnt/beta3-catenin signaling. Nat Genet. 2008;40(9):1130-1135.

30. Kasper M, et al. Selective modulation of Hedgehog/ GLI target gene expression by epidermal growth factor signaling in human keratinocytes. Mol Cell Biol. 2006;26(16):6283-6298.

31. Schnidar $\mathrm{H}$, et al. Epidermal growth factor receptor signaling synergizes with Hedgehog/GLI in oncogenic transformation via activation of the MEK/ERK/ JUN pathway. Cancer Res. 2009;69(4):1284-1292.

32. Wang GY, Wang J, Mancianti ML, Epstein EHJr. Basal cell carcinomas arise from hair follicle stem cells in Ptch1(+/-) mice. Cancer Cell. 2011;19(1):114-124.

33. Sneddon JB, et al. Bone morphogenetic protein antagonist gremlin 1 is widely expressed by cancerassociated stromal cells and can promote tumor cell proliferation. Proc Natl Acad Sci U S A. 2006; 103(40):14842-14847.

34. Bogovski P. Tumors of the skin. In: Turusov VS, Mohr U, eds. Pathology of Tumors in Laboratory Animals. Vol 2. Lyon, France: IARC Scientific Publications; 1994:11-12.

35. Grachtchouk V, et al. The magnitude of hedgehog signaling activity defines skin tumor phenotype. EMBO J. 2003;22(11):2741-2751.

36. Nilsson $M$, et al. Induction of basal cell carcinomas and trichoepitheliomas in mice overexpressing GLI-1. Proc Natl Acad Sci U S A. 2000;97(7):3438-3443.

37. Grachtchouk M, et al. Basal cell carcinomas in mice arise from hair follicle stem cells and multiple epithelial progenitor populations. J Clin Invest. 2011;121(5):1768-1781.

38. Jih DM, et al. Familial basaloid follicular hamartoma: lesional characterization and review of the literature. Am J Dermatopathol. 2003;25(2):130-137.

39. Morris RJ. Keratinocyte stem cells: targets for cutaneous carcinogens. J Clin Invest. 2000;106(1):3-8.

40. Visvader JE. Cells of origin in cancer. Nature. 2011;469(7330):314-322.

41. Blanpain C, Fuchs E. Epidermal homeostasis: a balancing act of stem cells in the skin. Nat Rev Mol Cell Biol. 2009;10(3):207-217.

42. Jaks V, Kasper M, Toftgard R. The hair follicle-a stem cell zoo. Exp Cell Res. 2010;316(8):1422-1428.

43. Youssef KK, et al. Identification of the cell lineage at the origin of basal cell carcinoma. Nat Cell Biol. 2010;12(3):299-305.

44. Jeong J, Mao J, Tenzen T, Kottmann AH, McMahon AP. Hedgehog signaling in the neural crest cells regulates the patterning and growth of facial primordia. Genes Dev. 2004;18(8):937-951.

45. Wong SY, Reiter JF. Wounding mobilizes hair follicle stem cells to form tumors. Proc Natl Acad Sci US A. 2011;108(10):4093-4098.

46. Ito $\mathrm{M}$, et al. Wnt-dependent de novo hair follicle regeneration in adult mouse skin after wounding. Nature. 2007;447(7142):316-320.

47. Ito M, et al. Stem cells in the hair follicle bulge contribute to wound repair but not to homeostasis of the epidermis. Nat Med. 2005;11(12):1351-1354.

48. Levy V, Lindon C, Zheng Y, Harfe BD, Morgan BA. Epidermal stem cells arise from the hair follicle after wounding. FASEB J. 2007;21(7):1358-1366.

49. Ridky TW, Khavari PA. The hair follicle bulge stem cell niche resists transformation by the hedgehog pathway. Cell Stem Cell. 2010;6(4):292-294.

50. Kasper M, et al. Wounding enhances epidermal tumorigenesis by recruiting hair follicle keratinocytes. Proc Natl Acad Sci U S A. 2011;108(10):4099-4104.

51. Barnes EA, Kong M, Ollendorff V, Donoghue DJ. 
Patched1 interacts with cyclin B1 to regulate cell cycle progression. EMBOJ. 2001;20(9):2214-2223.

52. Virchow R. Aetiologie der neoplastischen Geschwulste/ Pathogenie der neoplastischen Geschwulste. Berlin, Germany: Verlag von August Hirschwald; 1863.

53. Sexton M, Jones DB, Maloney ME. Histologic pattern analysis of basal cell carcinoma. Study of a series of 1039 consecutive neoplasms. J Am Acad Dermatol. 1990;23(6 pt 1):1118-1126.

54. Grachtchouk $M$, et al. Basal cell carcinomas in mice overexpressing Gli2 in skin. Nat Genet. 2000; 24(3):216-217.

55. Brownell I, Guevara E, Bai CB, Loomis CA, Joyner AL. Nerve-derived sonic hedgehog defines a niche for hair follicle stem cells capable of becoming epidermal stem cells. Cell Stem Cell. 2011;8(5):552-565.

56. Jaks V, et al. Lgr5 marks cycling, yet long-lived, hair follicle stem cells. Nat Genet. 2008;40(11):1291-1299.

57. Oro AE, Higgins K. Hair cycle regulation of Hedgehog signal reception. Dev Biol. 2003;255(2):238-248.

58. Mancuso M, et al. Hair cycle-dependent basal cell carcinoma tumorigenesis in Ptc1neo67/+ mice exposed to radiation. Cancer Res. 2006;66(13):6606-6614

59. Kwasniak LA, Garcia-Zuazaga J. Basal cell carcinoma: evidence-based medicine and review of treatment modalities. Int J Dermatol. 2011;50(6):645-658.

60. So PL, Tang JY, Epstein EH. Novel investigational drugs for basal cell carcinoma. Expert Opin Investig Drugs. 2010;19(9):1099-1112.

61. Binns W, James LF, Shupe JL, Everett G. A congenital cyclopian-type malformation in lambs induced by maternal ingestion of a range plant, veratrum californicum. Am J Vet Res. 1963;24:1164-1175.

62. Cooper MK, Porter JA, Young KE, Beachy PA. Teratogen-mediated inhibition of target tissue response to Shh signaling. Science. 1998; 280(5369):1603-1607.

63. Chen JK, Taipale J, Cooper MK, Beachy PA. Inhibition of Hedgehog signaling by direct binding of cyclopamine to Smoothened. Genes Dev. 2002; 16(21):2743-2748.

64. Athar M, et al. Inhibition of smoothened signaling prevents ultraviolet B-induced basal cell carcinomas through regulation of Fas expression and apoptosis. Cancer Res. 2004;64(20):7545-7552.

65 . Tabs S, Avci O. Induction of the differentiation and apoptosis of tumor cells in vivo with efficiency and selectivity. Eur J Dermatol. 2004;14(2):96-102.

66. Tremblay MR, et al. Semisynthetic cyclopamine analogues as potent and orally bioavailable hedgehog pathway antagonists. J Med Chem. 2008; 51(21):6646-6649.

67. Von Hoff DD, et al. Inhibition of the hedgehog pathway in advanced basal-cell carcinoma. $N$ Engl JMed. 2009;361(12):1164-1172

68. LoRusso PM, et al. Phase I trial of hedgehog pathway inhibitor vismodegib (GDC-0449) in patients with refractory, locally advanced or metastatic solid tumors. Clin Cancer Res. 2011;17(8):2502-2511.
69. Sekulic A, et al. A pivotal study evaluating efficacy and safety of the hedgehog pathway inhibitor (HPI) vismodegib (GDC-0449) in patients with locally advanced (la) or metastatic (m) basal cell carcinoma (BCC). Melanoma Research. 2011;21:e9.

70. Tang JY, et al. An investigator-initiated, phase II randomized, double-blind, placebo-controlled trial of GDC-0449 for prevention of BCCs in basal cell nevus syndrome (BCNS) patients [abstract]. Proceedings of the 102nd Annual Meeting of the American Association for Cancer Research. 2011:Abstract nr. LB-1.

71. Rudin CM, et al. A phase I study of IPI-926, a novel hedgehog pathway inhibitor, in patients (pts) with advanced or metastatic solid tumors. J Clin Oncol. 2011;29(1):abstract 3014.

72. Hall JM, Bell ML, Finger TE. Disruption of sonic hedgehog signaling alters growth and patterning of lingual taste papillae. Dev Biol. 2003;255(2):263-277.

73. St-Jacques B, et al. Sonic hedgehog signaling is essential for hair development. Curr Biol. 1998; 8(19):1058-1068

74. Skvara H, et al. Topical treatment of Basal cell carcinomas in nevoid Basal cell carcinoma syndrome with a smoothened inhibitor. J Invest Dermatol. 2011;131(8):1735-1744

75. Hutchin ME, et al. Sustained Hedgehog signaling is required for basal cell carcinoma proliferation and survival: conditional skin tumorigenesis recapitulates the hair growth cycle. Genes Dev. 2005; 19(2):214-223.

76. Rudin CM, et al. Treatment of medulloblastoma with hedgehog pathway inhibitor GDC-0449. N Engl J Med. 2009;361(12):1173-1178.

77. Yauch RL, et al. Smoothened mutation confers resistance to a Hedgehog pathway inhibitor in medulloblastoma. Science. 2009;326(5952):572-574.

78. Buonamici $S$, et al. Interfering with resistance to smoothened antagonists by inhibition of the PI3K pathway in medulloblastoma. Sci Transl Med. 2010;2(51):51 ra70

79. Dijkgraaf GJ, et al. Small molecule inhibition of GDC-0449 refractory smoothened mutants and downstream mechanisms of drug resistance. Cancer Res. 2011;71(2):435-444.

80. Kim J, et al. Itraconazole, a commonly used antifungal that inhibits Hedgehog pathway activity and cancer growth. Cancer Cell. 2010;17(4):388-399.

81. Lauth M, Bergstrom A, Shimokawa T, Toftgard R. Inhibition of GLI-mediated transcription and tumor cell growth by small-molecule antagonists. Proc Natl Acad Sci U S A. 2007;104(20):8455-8460.

82. Hyman JM, et al. Small-molecule inhibitors reveal multiple strategies for Hedgehog pathway blockade. Proc Natl Acad Sci U S A. 2009;106(33):14132-14137.

83. Beauchamp EM, et al. Arsenic trioxide inhibits human cancer cell growth and tumor development in mice by blocking Hedgehog/GLI pathway. J Clin Invest. 2011;121(1):148-160.

84. Kim J, Lee JJ, Gardner D, Beachy PA. Arsenic antag- onizes the Hedgehog pathway by preventing ciliary accumulation and reducing stability of the Gli2 transcriptional effector. Proc Natl Acad Sci U S A. 2010;107(30):13432-13437.

85. Jackson R, Grainge JW. Arsenic and cancer. Can Med Assoc J. 1975;113(5):396-401.

86. Bijlsma MF, Spek CA, Zivkovic D, van de Water S, Rezaee F, Peppelenbosch MP. Repression of smoothened by patched-dependent (pro-)vitamin D3 secretion. PLoS Biol. 2006;4(8):e232.

87. So PL, et al. Topical tazarotene chemoprevention reduces Basal cell carcinoma number and size in Ptch $1^{+/-}$mice exposed to ultraviolet or ionizing radiation. Cancer Res. 2004;64(13):4385-4389.

88. So PL, Fujimoto MA, Epstein EH Jr. Pharmacologic retinoid signaling and physiologic retinoic acid receptor signaling inhibit basal cell carcinoma tumorigenesis. Mol Cancer Ther. 2008;7(5):1275-1284.

89. Oro AE, Higgins KM, Hu Z, Bonifas JM, Epstein $\mathrm{EH} \mathrm{Jr}$, Scott MP. Basal cell carcinomas in mice overexpressing sonic hedgehog. Science. 1997; 276(5313):817-821.

90. Xie J, et al. Activating Smoothened mutations in sporadic basal-cell carcinoma. Nature. 1998; 391(6662):90-92.

91. Aszterbaum $M$, et al. Ultraviolet and ionizing radiation enhance the growth of BCCs and trichoblastomas in patched heterozygous knockout mice. Nat Med. 1995;5(11):1285-1291.

92. Sheng $H$, et al. Dissecting the oncogenic potential of Gli2: deletion of an $\mathrm{NH}(2)$-terminal fragment alters skin tumor phenotype. Cancer Res. 2002;62(18):5308-5316.

93. Mancuso M, et al. Basal cell carcinoma and its development: insights from radiation-induced tumors in Ptch1-deficient mice. Cancer Res. 2004; 64(3):934-941.

94. Svard J, et al. Genetic elimination of Suppressor of fused reveals an essential repressor function in the mammalian Hedgehog signaling pathway. Dev Cell. 2006;10(2):187-197.

95. Siggins SL, et al. The Hedgehog receptor Patched1 regulates myeloid and lymphoid progenitors by distinct cell-extrinsic mechanisms. Blood. 2009; 114(5):995-1004.

96. Mao J, et al. A novel somatic mouse model to survey tumorigenic potential applied to the Hedgehog pathway. Cancer Res. 2006;66(20):10171-10178.

97. Wong SY, et al. Primary cilia can both mediate and suppress Hedgehog pathway-dependent tumorigenesis. Nat Med. 2009;15(9):1055-1061.

98. Williams JA, et al. Identification of a small molecule inhibitor of the hedgehog signaling pathway: effects on basal cell carcinoma-like lesions. Proc Natl Acad Sci U S A. 2003;100(8):4616-4621.

99. Tang $\mathrm{T}$, et al. Targeting superficial or nodular Basal cell carcinoma with topically formulated small molecule inhibitor of smoothened. Clin Cancer Res. 2011;17(10):3378-3387. 